\title{
Mesalazine associated nephrogenic diabetes insipidus presenting as weight loss
}

\author{
E A Masson, J M Rhodes
}

\begin{abstract}
Nephrotoxicity in association with 5-aminosalicylic acid therapy is well recognised. In this patient the nephrotoxicity only became apparent after severe weight loss had occurred in association with nephrogenic diabetes insipidus. The patient aged 26 with ulcerative colitis received resin coated mesalazine (Asacol) $1200 \mathrm{mg} /$ day and lost $12 \mathrm{~kg}$ in weight over a four month period, only complaining of thirst towards the end of this period.
\end{abstract}

Interstitial nephritis has been associated with the administration of many drugs, ${ }^{1}$ particularly antibiotics, diuretics, and non-steroidal antiinflammatory agents. Blood concentrations of salicylate are normally low in patients receiving sulphasalazine or mesalazine (5-aminosalicylic acid, 5-ASA) for control of ulcerative colitis but there can be considerable individual variation in absorption of 5-ASA and there are also differences between the various preparations available. ${ }^{2}$ The development of nephrotic syndrome has also been reported in association with both of these drugs. ${ }^{34}$ We report a case where a patient receiving mesalazine for control of ulcerative colitis developed severe weight loss associated with nephrogenic diabetes insipidus which resolved rapidly after the drug was discontinued.

\section{Case report}

A 26 year old man presented in early 1989 with ulcerative colitis which was initially treated with steroid enemas and resin coated mesalazine (Asacol) $400 \mathrm{mg}$ thrice daily. In October he had a severe exacerbation of his colitis which necessitated hospital admission and treatment with parenteral corticosteroids. Mesalazine was stopped at this time. This episode settled and he was restarted on mesalazine in November, and continued to take oral corticosteroids in reducing doses until February 1990. Renal function was normal at this time (serum urea $4.7 \mathrm{mmol} / \mathrm{l}$, creatinine $84 \mathrm{~g} / \mathrm{l}$ ). In April 1990 he was well with a serum C-reactive protein concentration of $2 \mathrm{mg} /$ 1 , and was iron deficient for which he received a course of oral ferrous sulphate. Over the next four months he developed anorexia, general malaise and weight loss although he did not have any symptoms of active colitis. By August he had lost a total of $12 \mathrm{~kg}$ and was by then complaining for the first time of severe polyuria and polydipsia. He was admitted for investigation which revealed a normal blood glucose $(4.5 \mathrm{mmol} / \mathrm{l})$ and normal barium enema. He had microscopic haematuria with a minor degree of proteinuria (dipstick ++ ve). Serum albumin was normal but renal function was impaired (serum creatinine $165 \mathrm{~mol} / \mathrm{l}$ ). Serum C-reactive protein was $132 \mathrm{mg} /$ 1. Intravenous urography was normal but renal ultrasound showed prominence of the pyramids indicative of renal parenchymal pathology. Serum osmolality was $293 \mathrm{mosmol} / \mathrm{l}$ (reference range 280-290) with a urine osmolality of 151 mosmol/l suggesting a loss of concentrating ability although a formal water deprivation test was not done. A diagnosis of drug induced interstitial nephritis was suspected and mesalazine was stopped with an immediate improvement in his condition. The polyuria and polydipsia resolved within three days and he gained $4 \mathrm{~kg}$ in weight over the following week with resolution of anorexia and malaise. Within three months renal function had returned to normal and he had gained a further $8 \mathrm{~kg}$ in weight. Because of the previous severity of his colitis he was cautiously started on maintenance sulphasalazine with careful monitoring of urine protein and renal function. He has been taking sulphasalazine $1 \mathrm{~g}$ twice daily for 10 months and continues to have a normal serum creatinine and no proteinuria or microscopic haematuria.

\section{Discussion}

Allergic interstitial nephritis occurs as an idiosyncratic reaction to many drugs and the clinical course can be extremely variable. Recovery after withdrawal of the drug is usual, but may be slow. With some drugs (such as allopurinol, nephrotoxicity of this type can be dose related.' In the treatment of ulcerative colitis with oral preparations of 5-aminosalicylic acid (5-ASA) serum concentrations of salicylate are usually low. Serum concentrations of 5-ASA and n-acetyl 5-ASA after administration of resin coated 5-ASA had an earlier and higher peak when compared with equivalent doses of sulphasalazine in a single dose study, but urinary excretion was similar. ${ }^{5}$ Moreover systemic absorption is variable in patients with colitis. ${ }^{67}$ Although most free 5-ASA is acetylated to its less toxic metabolite n-acetyl 5-ASA in the gut mucosa resin coated preparations may allow
University Department of Medicine and Wa E A Masson MM Rhodes 
rapid release in the small bowel which may overload this process. ${ }^{8}$

5-ASA is structurally related to phenacetin, and while high intravenous doses cause renal damage in animals this has not been observed in clinical trials of oral preparations. ${ }^{9}$ The Committee on Safety of Medicines has, however, recently issued a warning of nephrotoxic reactions to mesalazine ${ }^{10}$ which include biopsy proven interstitial nephritis. It is possible that dose related renal toxicity of non-acetylated 5-ASA may arise with mechanical or $\mathrm{pH}$ dependent release preparations which may not be seen when the cleavage of an azo bond is responsible for colonic delivery. We do not know if any other patient who suffered renal toxicity with a delayed release 5-ASA preparation has subsequently tolerated sulphasalazine. In the case reported here proteinuria, renal failure, loss of concentrating ability and microscopic haematuria all suggested the diagnosis of interstitial nephritis. The dramatic symptomatic and biochemical recovery which followed withdrawal of mesalazine made renal biopsy and specific treatment unnecessary. Previous reports have associated the development of nephrotic syndrome with sulphasalazine and mesalazine, perhaps by similar mechanisms. ${ }^{34}$ There has been one report from Canada ${ }^{11}$ of mesalazine usage associated with acute polyuria and polydipsia which resolved on withdrawal of treatment, but this was not associated with systemic illness or weight loss.

Drug related interstitial nephritis should be considered as a possible diagnosis in patients with ulcerative colitis who lose weight unexpectedly. This case reinforces the need to monitor urine protein and renal function in patients receiving 5-aminosalicylic acid therapy for ulcerative colitis.

1 Cameron JS. Allergic interstitial nephritis: clinical features and pathogenesis. $Q \mathcal{F}$ Med 1988; 66: 97-115.

2 Cristensen LA, Fallingborg J, Abildgaard K, Jacobsen BA, Sanchez G, Hansen SH, et al. Topical and systemic availability of 5-amino salicylate: comparisons of three controlled release preparations in man. Aliment Pharmacol Therap 1990; 4: 523-33.

3 Barbour VM, Williams PF. Nephrotic syndrome associated with sulphasalazine. $B M \mathcal{F}$ 1990; 301: 818 .

4 Norvis BH, Korzets Z, Chen P, Bernheim J. Nephrotic Norvis $\mathrm{BH}$, Korzets $\mathrm{Z}$, Chen $\mathrm{P}$, Bernheim J. Nephrotic
syndrome after treatment with 5-aminosalicylic acid. $B M \mathcal{F}$ 1990; 296: 1442 .

5 Dew MJ, Ebden P, Kidwai NS, Lee G, Evans BK, Rhodes J. Comparison of the absorption and metabolism of sulphasalazine and acrylic-coated 5-amino salicylic acid in normal subjects and patients with colitis. $\mathrm{Br} \mathcal{F}$ Pharmacol $1984 ; 17: 474-6$

6 Dew MJ, Ryder REJ, Evans N, Evans BK, Rhodes J. Colonic release of 5-aminosalicylic acid from an oral preparation in active ulcerative colitis $\mathrm{Br} 7 \mathrm{Clin}$ Pharmacol 1983; 16 : 185-7.

7 Staerk Laursen L, Stokholm M, Bukhave K, Rask-Madsen J, Lauritsen $K$. Disposition of 5 -aminosalicylic acid by olsalazine and three mesalazine preparations in patients with ulcerative colitis: comparison of intraluminal colonic conulcerative colitis: comparison of intraluminal colonic concentrations,

8 Hayllar J, Bjarnson L. Sulphasalazine in ulcerative colitis: in memoriam? Gut 1991; 32: 462-3.

9 Dew MJ. Sulphasalazine and aminosalicylates in treatment. In: Allan R, Alexander-Williams J, Hawkins C, Keighley M, eds. Inflammatory bowel diseases. 2nd ed., Oxford: Churchill Livingstone, 1990: 365-72.

10 Committee on Safety of Medicines: Current problems: no 30 , Committee on Safety of Medicines, London, 1990.

11 Mehta RP. Acute interstitial nephritis due to 5-aminosalicylic acid. Can Med Assoc $₹$ 1990; 143: 1031-2. 